Disclosure of Interests: None declared

DOI: 10.1136/annrheumdis-2020-eular.5904

\begin{tabular}{|l|l}
\hline AB0189 & ASSESSMENT OF POWER DOPPLER SYNOVITIS IN \\
RHEUMATOID ARTHRITIS PATIENTS WITH CLINICAL \\
REMISSION
\end{tabular}

R. Fakhfakh ${ }^{1}$, N. El Amri ${ }^{1}$, K. Baccouche ${ }^{1}$, H. Zeglaoui ${ }^{1}$, E. Bouajina ${ }^{1}$. ${ }^{1}$ Farhat Hached Hospital, Rheumatology, Sousse, Tunisia

Background: Ultrasound-detected synovitis, mainly synovial Doppler signal, has shown predictive value in relation to radiographic damage progression and disease flare or relapse in rheumatoid arthritis (RA) patients with clinical remission. Objectives: The aim of the study was to analyze the correlation between power Doppler scores and clinical/laboratory and radiographic data in clinical remission RA patients.

Methods: Cross-sectional study including patients with RA in clinical remission defined by: DAS28ESR $\leq 2.6$, without disease flare or changes in therapy in the previous 6 months. Each patient underwent ultrasound: B-mode and PD assessments of 36 joints and 20 tendons in the Rheumatology Department over a period of 6 month. Synovitis and tenosynovitis were defined and scored according to the Outcome Measures in Rheumatology Clinical Trials (OMERACT). Radiological measurements included the modified Sharp/van der Heijde method (SHS). Functional capacity was assessed by the Health Assessment Questionnaire (HAQ).

Results: Thirty two patients were enrolled, the mean age was $53.7 \pm 13.4$ and $75 \%$ were female. The mean disease duration was 15 years \pm 8.8 . Subclinical synovitis were the most frequent in wrist $(56.3 \%), 2^{\text {nd }}$ metacarpophalangeal joints $(28.1 \%)$ and $2^{\text {nd }}$ metatarsophalangeal joints $(29 \%)$. The mean subclinical synovitis/ tenosynovitis numbers was $4 \pm 3.1$ per patient. Synovial hypertrophy and B mode tenosynovitis were detected in $93.8 \%: 71.3 \%$ had a grade $=2$ and $9.8 \%$ had a grade $=3$. Total B mode score was correlated only with the SHS score in the feet ( $r: 0.4$, p: 0.03 ). PD signal was detected in $62.5 \%$ of patients: $37.5 \%$ had a grade $=2$ and $9.4 \%$ had a grade $=3$. Total PD score was correlated with DAS28 (r:0.42, p:0.02), the SHS score in the hands ( $r: 0.39, p: 0.03)$ and in the feet $(r: 0.5, p: 0.007)$, synovial hypertrophy ( $r: 0.6, p: 0.0001)$ and $\mathrm{HAQ}(r: 0.32$, $\mathrm{p}: 0.06)$. No correlation was found with CDAI, SDAI, swollen joint counts, tender joint counts, patient global health assessment, erythrocyte sedimentation rate, $\mathrm{C}$-reactive protein, rheumatoid factor and anti-cyclic citrullinated peptide, biologic treatment.

Conclusion: Synovial hypertrophy and PD signal were frequent in RA remission. PD signal was associated with RA activity, radiologic damage and functional capacity.

References:

11] Yan Geng \& Jingjing Han \& Xuerong Deng and al. Presence of power Doppler synovitis in rheumatoid arthritis patients with synthetic and/or biological disease-modifying anti-rheumatic drug-induced clinical remission: experience from a Chinese cohort. Clinical Rheumatology 2014. DOI 10.1007/ s10067-014-2634-y

Disclosure of Interests: None declared

DOI: 10.1136/annrheumdis-2020-eular.6064

\section{AB0190 DO IT FAST! EARLY ASSESSMENT BY A RHEUMATOLOGIST INCREASES THE CHANCES OF RHEUMATOID ARTHRITIS BEING TREATED WITHIN THE "WINDOW OF OPPORTUNITY"}

C. Albuquerque ${ }^{1}$, A. P. Gomides ${ }^{1}$, A. B. Vargas-Santos ${ }^{2}$, C. Brenol ${ }^{3}$, I. Pereira ${ }^{4}$, K. Bonfiglioli ${ }^{5}$, M. Bertolo ${ }^{6}$, M. F. Guimarães ${ }^{7}$, M. Sauma ${ }^{8}$, P. Louzada Jr ${ }^{9}$, R. Giorgi ${ }^{10}$, S. Radominsky ${ }^{11}$, L. Mota ${ }^{1}$, G. Castelar-Pinheiro ${ }^{2} .{ }^{1}$ Universidade de Brasilia, Brasilia, Brazil; ' Universidade do Rio de Janeiro, Rio de Janeiro, Brazil; ${ }^{3}$ Universidade Federal do Rio Grande do Sul, Porto Alegre, Brazil; ${ }^{4}$ Universidade Federal de Santa Catarina, Florianópolis, Brazil; ${ }^{5}$ Universidade de São Paulo, São Paulo, Brazil; ${ }^{6}$ Universidade Estadual de Campinas, Campinas, Brazil; ${ }^{7}$ Universidade Federal de Minas Gerais, Belo Horizonte, Brazil; ${ }^{8}$ Universidade Federal do Pará, Belém, Brazil; ${ }^{9}$ Universidade de São Paulo - Ribeirão Preto, Ribeirão Preto, Brazil; ${ }^{10} \mathrm{Hospital}$ do Servidor Público Estadual de São Paulo, Sâo Paulo, Brazil; ${ }^{11}$ Universidade Federal do Rio Grande do Sul, Porto Alegre, Brazil

Background: The current concept of treating rheumatoid arthritis RA patients emphasizes the importance of early diagnosis and early initiation of disease-modifying drugs (DMARD) for a better prognosis of these patients. Objectives: To evaluate the impact of rheumatologic evaluation on the diagnosis of RA patients, as well as on the initiation of DMARD and on the clinical control of disease activity of these patients under real-life conditions.

Methods: The REAL study included RA patients attending eleven public hospitals, from different regions of Brazil. All subjects met the ARA (1987) or ACR/
EULAR (2010) RA classification criteria. Subjects were submitted to clinical interview with physical exam and review of medical records. Specialized assessment was defined as sequentially "early", when the rheumatologist was the $1^{\text {st }}$ or $2^{\text {nd }}$ consulted physician, and sequentially "late", when the rheumatologist was consulted after two or more other doctors. Welch's $t$, Mann-Whitney's U, chi-square and Spearman's rho tests were used to test hypotheses, at significance level of 0.05 . The study was approved by local ethics committees and all participants granted informed consent.

Results: 1057 RA patients were assessed; 89.4\% ( $n=945)$ female; 56.5\% $(n=597)$ white; mean (SD) age of 56.9 (11.5) years; mean (SD) disease duration of 173.1 (114.5) months. Median [IQR] delay from symptoms onset to RA diagnosis and to the first DMARD both equaled $12[6,36]$ months. Only $28.7 \%$ received a DMARD within 6 months of symptoms onset, and $13.1 \%$ within 3 months. Most patients (64.6\%) sought a general practitioner first, but $80.7 \%$ were finally diagnosed only upon rheumatologist consultation. For $28.8 \%$, the rheumatologist was consulted after two or more other doctors. Early specialized assessment resulted in higher chances of receiving a DMARD within 6 months (OR 2.77; 95\%Cl [1.93, 3.97]) and within 3 months (OR 2.57; 95\%C [1.54, 4.27]) of RA onset. Late assessment was associated with lower chances of being in remission or low disease activity upon study inclusion (OR 0.53 ; $95 \% \mathrm{Cl}[0.39,0.72])$. Patients assessed early by the rheumatologist, compared to those assessed late, showed lower (mean [SD]) HAQ scores (0.877 [0.715] vs. 1.074 [0.857]; $p<0.001$ ) and DAS28-CRP scores (3.20 [1.32] vs. 3.45 [1.48] $\mathrm{p}=0.02)$, and shorter delays to RA diagnosis (26.9 [46.7] vs. 44.6 [60.1] months $\mathrm{p}<0.001)$ and to use the first DMARD (32.5 [58.5] vs. 50.6 [69.9] months $\mathrm{p}<0.001)$. The delay to initiate a DMARD was strongly correlated to that of diagnosing RA (rho 0.816; $p<0.001$ ).

Conclusion: Most RA patients missed the window of opportunity to early treatment. Treatment delay strongly correlated with delay in diagnosis, which critically depended on the input from the rheumatologist. Late rheumatologist assessment was associated with lower chances of early RA treatment and with worse outcomes. Failure in direct transition from primary to specialized care was a common problem that needs to be solved.

Disclosure of Interests: Cleandro Albuquerque Grant/research support from: Has received personal fees and/or non-financial support from Pfizer AbbVie, AstraZeneca, Janssen, Bristol-Myers Squibb, Roche, Novartis and UCB, Consultant of: Has received personal fees and/or non-financial support from Pfizer, AbbVie, AstraZeneca, Janssen, Bristol-Myers Squibb, Roche, Novartis and UCB, Paid instructor for: Has received personal fees and/or non-financial support from Pfizer, AbbVie, AstraZeneca, Janssen Bristol-Myers Squibb, Roche, Novartis and UCB, Speakers bureau: Has received personal fees and/or non-financial support from Pfizer, AbbVie AstraZeneca, Janssen, Bristol-Myers Squibb, Roche, Novartis and UCB Ana Paula Gomides Consultant of: Abvvie, Ana Beatriz Vargas-Santos Grant/research support from: Has received supporting for international medical events from AbbVie and Janssen, Claiton Brenol: None declared, Ivanio Pereira Grant/research support from: Has received consulting fees, speaking fees and supporting for internationals congresses from Roche, Pfizer, UCB Pharma, Eli-Lilly, Abbvie and Janssen, Consultant of: Has received consulting fees, speaking fees and supporting for internationals congresses from Roche, Pfizer, UCB Pharma, Eli-Lilly, Abbvie and Janssen, Paid instructor for: Has received consulting fees, speaking fees and supporting for internationals congresses from Roche, Pfizer, UCB Pharma, Eli-Lilly, Abbvie and Janssen, Speakers bureau: Has received consulting fees, speaking fees and supporting for internationals congresses from Roche, Pfizer, UCB Pharma Eli-Lilly, Abbvie and Janssen, Karina Bonfiglioli Consultant of: Roche, Abbvie, Pfizer, Janssen and BMS, Manoel Bertolo Grant/research support from: Has participated in clinical and/or experimental studies related to this work and sponsored by Roche; has delivered speeches at events related to this work and sponsored by AbbVie and Pfizer, Consultant of: Has participated in clinical and/or experimental studies related to this work and sponsored by Roche; has delivered speeches at events related to this work and sponsored by AbbVie and Pfizer, Paid instructor for: Has participated in clinical and/ or experimental studies related to this work and sponsored by Roche; has delivered speeches at events related to this work and sponsored by AbbVie and Pfizer, Speakers bureau: Has participated in clinical and/or experimental studies related to this work and sponsored by Roche; has delivered speeches at events related to this work and sponsored by AbbVie and Pfizer Maria Fernanda Guimarães: None declared, Maria Sauma: None declared, Paulo Louzada Jr Grant/research support from: Has received supporting for internationals congresses from Bristol-Myers Squibb, UCB and consulting fees from Pfizer, Paid instructor for: Has received supporting for internationals congresses from Bristol-Myers Squibb, UCB and consulting fees from Pfizer, Speakers bureau: Has received supporting for internationals congresses from Bristol-Myers Squibb, UCB and consulting fees from Pfizer, Rina Giorgi Grant/research support from: Has received consulting fees, speaking fees and supporting for internationals congresses from Roche 